\title{
El Niño as a predictor of round sardinella distribution along the northwest African coast
}

\author{
Jorge López-Parages ${ }^{\mathrm{a}, \mathrm{b}, \mathrm{f}, *}$, Pierre-Amaël Auger ${ }^{\mathrm{c}, \mathrm{d}}$, Belén \\ Rodríguez-Fonseca $^{\mathrm{a}}$, Noel Keenlyside ${ }^{\mathrm{e}}$, Carlo Gaetan ${ }^{\mathrm{b}}$, Angelo Rubino ${ }^{\mathrm{b}}$, \\ Maeregu W. Arisido ${ }^{\mathrm{b}}$, Timothée Brochier ${ }^{\mathrm{g}}$ \\ ${ }^{a}$ Dpto de Física de la Tierra y Astrofísica, UCM-IGEO, Complutense University of \\ Madrid, Spain \\ ${ }^{b}$ Dpto di Scienze Ambientali, Informatica e Statistica, Ca Foscari University of Venice, \\ Italy \\ ${ }^{c}$ Instituto Milenio de Oceanografía and Pontificia Universidad Católica de Valparaíso, \\ Valparaíso, Chile \\ ${ }^{d}$ Laboratoire d'Ocanographie Physique et Spatiale (LOPS), IUEM, Brest Universit, \\ CNRS, IRD, Ifremer, Brest, France \\ ${ }^{e}$ Bjerknes Centre for Climate Research, Univ. of Bergen, Norway \\ ${ }^{f}$ CERFACS/CNRS, Climate Modelling and Global Change Team, 42 avenue Gaspard \\ Coriolis, 31057 Toulouse, France \\ ${ }^{g}$ Institut de Recherche pour le Dveloppement (IRD), UMMISCO, Sorbonne Universit, \\ Univertis Cheikh Anta Diop, Dakar, Senegal
}

\begin{abstract}
The El Niño Southern Oscillation (ENSO) produces global marine environment conditions that can cause changes in abundance and distribution of distant fish populations worldwide. Understanding mechanisms acting locally on fish population dynamics is crucial to develop forecast skill useful for fisheries management. The present work addresses the role played by ENSO on the round sardinella population biomass and distribution in the central-southern portion of the Canary Current Upwelling System (CCUS). A combined physical-biogeochemical framework is used to understand the climate influence on the hydrodynamical conditions in the study area. Then, an evolutionary individual-based model is used to simulate the round sardinella spatio-temporal biomass variability. According to model experiments, anomalous oceanographic conditions forced by El Niño along the African
\end{abstract}

\footnotetext{
${ }^{*}$ Corresponding author

Email address: jlopez@cerfacs.fr (Jorge López-Parages)
} 
coast cause anomalies in the latitudinal migration pattern of the species. A robust anomalous increase and decrease of the simulated round sardinella biomass is identified in winter off the Cape Blanc and the Saharan coast region, respectively, in response to El Niño variations. The resultant anomalous pattern is an alteration of the normal migration between the Saharan and the Mauritanian waters. It is primarily explained by the modulating role that El Niño exerts on the currents off Cape Blanc, modifying therefore the normal migration of round sardinella in the search of acceptable temperature conditions. This climate signature can be potentially predicted up to six months in advance based on El Niño conditions in the Pacific.

Keywords: El Nino, Sardinella aurita, Coastal upwelling, Dynamical oceanography, Atmospheric sciences

\section{Introduction}

\subsection{The round sardinella in the CCUS}

Small pelagic fishes populations in the so-called Eastern Boundary Upwelling Systems (EBUS) are particularly sensitive to global climate change and variability (Bakun, 1990, Bakun et al., 2015, Brochier et al., 2013). These systems, moreover, are of special biological and social importance (Fréon et al., 2009), as they jointly contribute to more than $20 \%$ of global fish catches and more than $7 \%$ of global marine primary production although they only cover approximately $1 \%$ of the total ocean surface (Pauly and Christensen, 1995). The socio-economic relevance of fisheries is especially clear for the Canary Current Upwelling System (CCUS) because of its impact on the economies of the northwest African countries (Failler, 2014). This is particularly true in the case of small pelagic fisheries, as they are the main pelagic fisheries in this region in terms of commercial landings $(\sim 450.000$ tons per year; Braham et al., 2014).

The CCUS is characterized by a marked spatial and seasonal variability (Chavez and Messié, 2009), especially south of Cape Blanc $\left(\sim 20^{\circ} \mathrm{N}\right.$; Carr and Kearns, 2003) and north of the Canary Islands $\left(\sim 27^{\circ} \mathrm{N}\right.$; Messié and Chavez, 2015), which is associated with the latitudinal migration of the Intertropical Convergence Zone and the accompanying evolution of the Azores high (Wooster et al., 1976). This variability seems to affect the spatial distribution of migratory fish species such as Sardinella aurita (Valenciennes, 1847), 
which is the most abundant small pelagic fish in the Senegalese-Mauritanian region. This species, usually called round sardinella, undertakes large northsouth migrations over the continental shelf along northwest Africa, with the area of maximum abundance being located approximately between $11^{\circ} \mathrm{N}$ and $25^{\circ} \mathrm{N}$ (Boëly et al., 1978). Data on fishing effort, fish length distribution, and coastal environmental variability have facilitated recent refinement of scientific understating concerning the details of this migration pattern (Braham et al., 2014, Corten et al., 2012, 2017). Recently Brochier et al. (2018) suggested that the migration results from 1) an interplay between sea temperature and food availability conditions which both influence the habitat quality of round sardinella, and 2) the effect that coastal currents exert on the passive advection component of round sardinella horizontal movements. These environmental variables (sea temperature, food availability, and currents) also exhibit clear year-to-year differences that modify the seasonal cycle of the CCUS (Benazzouz et al., 2014). However, the mechanisms behind this interannual variability are not well understood. Disentangling the climate influences on the alongshore variability of sea temperature, food abundance, and coastal currents in northwest Africa would shed light on the related response of the round sardinella population. This understanding is crucial to the development of useful prediction tools for the cooperative management of fish stocks that span political boundaries, and is thus of great importance to the economy and food security of the countries in this region (Failler, 2014).

\subsection{Global climate as a forcing of round sardinella in the CCUS}

Coastal upwelling involves the offshore transport of surface water and its replacement by deep, cold and nutrient-rich waters via Ekman dynamics. This is, therefore, a wind-driven process modulated by the intensity of the alongshore winds (Barton et al., 1998). Thus, the interannual variability of surface winds blowing southward alters coastal upwelling, which in turn triggers changes in the ocean mixed-layer temperature, primary productivity, and currents. Thermodynamic processes forced by the surface winds can also alter the upper ocean through heat flux exchanges. Both of the aforementioned mechanisms (dynamical upwelling and thermodynamic heat fluxes) are therefore related to the variability of the surface winds (Polo et al., 2005) and have the potential to alter the round sardinella distribution. Thus, the round sardinella population size and distribution off northwest Africa could be related to large-scale patterns of climate variability due to their impact 
on the trade winds blowing in this region (Binet, 1988).

Understanding the remote responses of fish populations to climate variations is a long standing concern of major importance and broad scientific interest (Overland et al., 2010, Báez et al., 2019). In the case of the CCUS, this issue has been explored in the past, and the results seem to depend on several factors including the chosen methodology. An example of this is the relation with the North Atlantic Oscillation (NAO) which is the dominant atmospheric variability mode over the North Atlantic in boreal winter (Czaja et al., 2002, Visbeck et al., 2003). The occurrence of upwelling-favorable winds along the northwest African coast is strongly related to the location and strength of the North Atlantic subtropical high (the Azores high) and hence, to the NAO (Meiners et al., 2010). However, recent studies in the CCUS suggest a significant correlation between the NAO and the coastal upwelling intensity when this is derived from the wind stress, but not when this is constructed from the difference in sea surface temperature (hereinafter SST) between the coast and the open ocean (Benazzouz et al., 2014, Cropper et al., 2014, Narayan et al., 2010). The El Niño-Southern Oscillation (ENSO) phenomenon, which is the dominant pattern of global climate variability at interannual timescales, also impacts the tropical North Atlantic (TNA) through a variety of mechanisms (Giannini et al., 2001, Wang, 2004, Lee et al., 2008, García-Serrano et al., 2017). However, few works have analyzed the impact of ENSO on the CCUS and, as in the case of NAO, they conflict on whether a significant signature exists (see e.g., Roy and Reason, 2001 and Oettli et al., 2016). Estimating the local signature of these global climate modes on round sardinella population in the CCUS is a priori even harder, as the available abundance data, even with state of the art observational capabilities, are scarce or of low quality. There are also intrinsic limitations in round sardinella catch data associated with the difficulty of distinguishing environmental influences (i.e., not directly related to changes in human activities) and human-related influences. The second includes variability of the market demand, changes in fishing gear and fleet composition, and improvements in fishermen technical skill over time (see e.g., discussion in Bez and Braham, 2014). The recent and interesting observational analyses of the CCUS (see e.g., Braham et al., 2014) do not clarify the multiple environmental factors impacting round sardinella spatio-temporal variability.

New approaches are required to move beyond these conflicting results. 
Despite their deficiencies, models provide a means to overcome the inherent limitations of observational analysis. For example, investigation of model simulations permit researchers to isolate the climate-related responses from the direct human influence. In the present study, a modeling approach has been used to investigate the influence of ENSO on the interannual variability in the biomass and spatial distribution of a simulated round sardinella population in the central-southern portion of the CCUS.

\section{Material and methods}

\subsection{Modeling strategy}

The study region (hereinafter referred as CCUS; see Fig. 1) is the upper ocean east of $24^{\circ} \mathrm{W}$ and between $10^{\circ} \mathrm{N}$ and $35^{\circ} \mathrm{N}$. This geographic area is divided in three distinct regions according to the intensity and seasonal variability of upwelling-favorable winds: the Mauritania-Senegalese zone where the upwelling is seasonal $\left(12^{\circ} \mathrm{N}-19^{\circ} \mathrm{N}\right)$, the zone off the Saharan bank $\left(21^{\circ} \mathrm{N}\right.$ $\left.26^{\circ} \mathrm{N}\right)$, and the north Moroccan coast $\left(26^{\circ} \mathrm{N}-35^{\circ} \mathrm{N}\right)$, the last two being characterized by year-round upwelling-favorable winds but with different intensities (Benazzouz et al., 2014).

In this study, a recently developed bio-climatic modeling strategy has been applied. This model approach has been proven as an efficient tool for describing realistic responses of primary productivity and round sardinella to the environment (Auger et al., 2016, Brochier et al., 2018). A scheme of the modeling strategy applied in this study is shown in Fig. 2. Two different parts are identified. In a first step, a hindcast simulation from a coupled hydrodynamic/biogeochemical model produces a realistic 3-D simulation of variability in the fish environment in the CCUS over the period 1980-2009. The hydrodynamic environment is simulated by the Regional Oceanic Modeling System ROMS (Shchepetkin and McWilliams, 2005) with an $\sim 8-\mathrm{km}$ resolution and 32 vertical sigma-levels for the CCUS, while the biogeochemical environment is simulated by the PISCES model (Pelagic Interaction Scheme for Carbon and Ecosystem Studies; see Aumont et al., 2003 and Aumont and Bopp, 2006) which simulates phytoplankton and zooplankton productivity based on the uptake of nutrients dispersed by ROMS currents. In the present work, the ROMS-PISCES coupled model was forced with the CFSR atmospheric reanalysis (Saha et al., 2010) at a 6-h timescale and with $1 / 3^{\circ}$ resolution, and the lateral open boundary conditions are from 
monthly model outputs from a simulation of the North Atlantic Ocean in which PISCES is forced by the NEMO hydrodynamic model (Nucleus for European Modelling of the Ocean; Madec, 2008). Please see Auger et al. (2015) for a description of the ROMS-PISCES model configuration, the forcing datasets, and the validation of model results using satellite data observations. In a second step, the evolutionary individual-based model Evol-DEB (https://github.com/tbrochier/EvolDEB) was forced by physical and biogeochemical outputs from ROMS-PISCES. Evol-DEB is an individual-based model that has been proven as an efficient tool to characterize the effect of climate on round sardinella population variables, accounting for environmental (e.g., currents, temperature and primary/secondary production) and biological (e.g., fish growth, mortality) factors. The performance of Evol$D E B$ has been assessed in the study area through a variety of comparisons including: 1) CPUE (Catch Per Unit Effort) indices calculated from local fisheries monitoring in Senegal and Mauritania, 2) observations of round sardinella body-length distribution from artisanal and industrial fisheries, scientific sampling, and oceanographic research vessels, 3) acoustic observations from oceanographic research vessels, and finally 4) qualitative ecological knowledge from Senegalese fishermen. Brochier et al. (2018) provide a full description of Evol-DEB and the validation procedure. The three main environmental factors influencing the round sardinella dynamics that were tested in the Evol-DEB simulations and investigated in the current study were: 1) the currents, 2) the temperature, and 3) the food distribution (from a proxy based on the concentration of plankton in PISCES), each of them averaged over the ocean mixed layer. As described in Brochier et al. (2018), the temperature and food proxy were combined to define the Habitat Quality Index (HQI). In the Evol-DEB framework, each aggregation of round sardinella or super-individuals is affected by the HQI in such a way that the maximization of this HQI according to the environmental conditions determines the chance of survival of each super-individual. Round sardinella dynamics also depend on specific round sardinella parameters such as: 1) the swimming capacity, 2) the growth rate, 3) the functional response to the food, and 4) the preferred temperature. Please see Brochier et al. (2018) for details.

In the present study, the Evol-DEB configuration that most realistically captures the response of round sardinella to the environment among all those tested in Brochier et al. (2018) was used: that in which adult populations are sensitive to the currents, and to the temperature and food distributions, 
with maximum swimming speed of 4.5 body-length per second, and with the preferred temperature determined by the corresponding natal temperature. Each Evol-DEB simulation lasted for 30 years, from 1980 to 2009, with a seeding procedure taking place in 1980. The 1980-1984 period was viewed as a spin-up period, considering that the maximum longevity of superindividuals is $\sim 4.5$ years. The choice of the initialization of environmental conditions was shown to have little effect on the subsequent emerging interannual variability, resulting therefore in an effective output period of 25 years (from 1985 to 2009). Please note that although the environmental forcings which influence round sardinella variability in $E v o l-D E B$ are the ocean variables provided by ROMS-PISCES, the atmospheric forcing from the CFSR reanalysis used to run the ROMS-PISCES model do contain information of any potential teleconnection between the global climate and the local round sardinella population biomass. Therefore, the described comprehensive modeling framework (ROMS-PISCES and Evol-DEB) will capture a significant response to global climate forcing, depending on the forcing persistence and the noise generated internally by the models. If any climate-round sardinella teleconnection is identified in the analysis of final model outputs (Fig. 2), it must have entered into the model setup through the applied boundary conditions, and it should be strong enough to be passed among the physicalbiogeochemical-ecosystem components of the models involved.

\subsection{Exploring the relation with the global climate}

The aim of this study was to understand how the latitudinal distribution of simulated adult round sardinella biomass over the northwest African continental shelf is altered by changes in the local environmental conditions and to explore the possible role played by remote climate forcings. The biomass over the continental shelf captures most of the north-south round sardinella variability, as the stocks are generally tied to the coastal areas where the highest food production occurs. This feature is well represented by the ROMS-PISCES-Evol-DEB model framework (Figs. 3a-b). Based on the latter, various latitude vs months Hovmöller diagrams were plotted for different fields by averaging the corresponding variable across longitudes (Figs. 3c-f). To reduce the degrees of freedom and to efficiently characterize round sardinella variability, Empirical Orthogonal Function (EOF; Lorenz, 1956) analysis was performed on the yearly Hovmöllers of modeled round sardinella biomass (anomalous round sardinella biomass averaged in longitude 


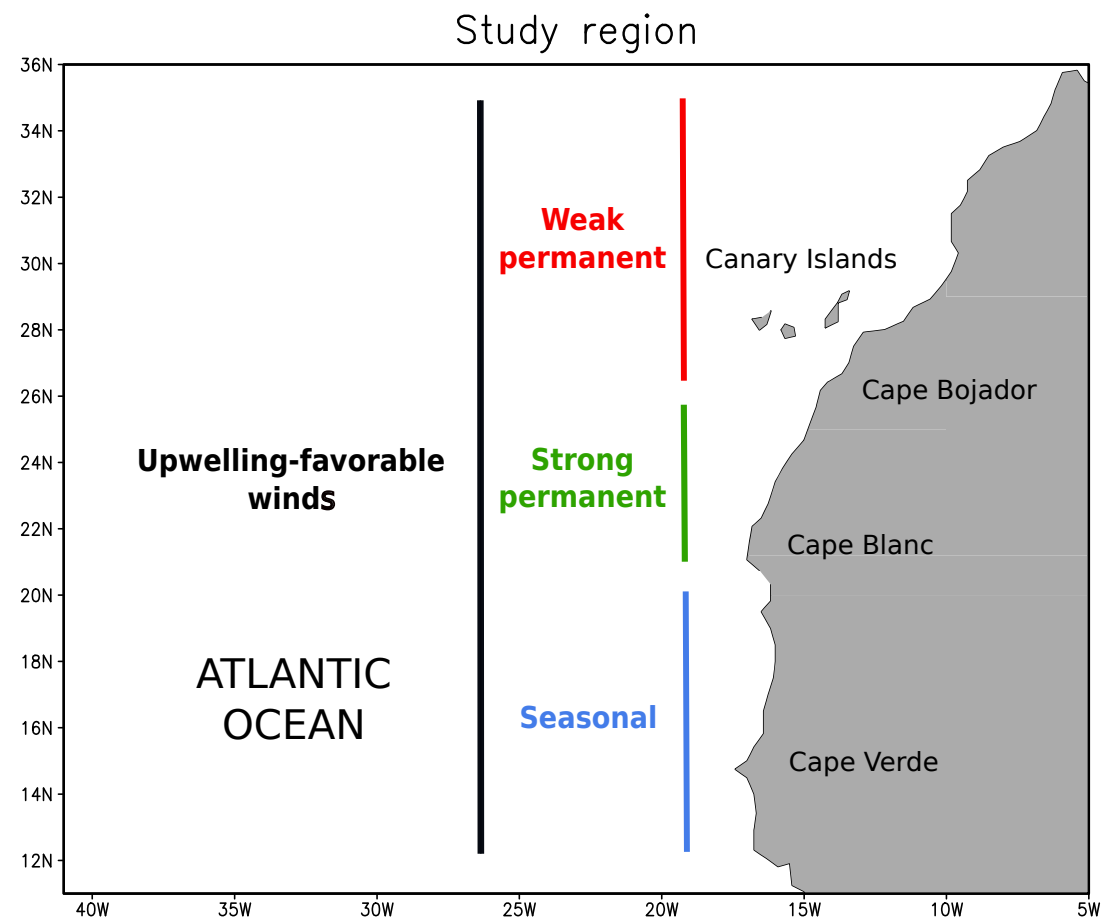

Figure 1: Study region and upwelling zones inside it. This figure is only used for illustrative purposes.

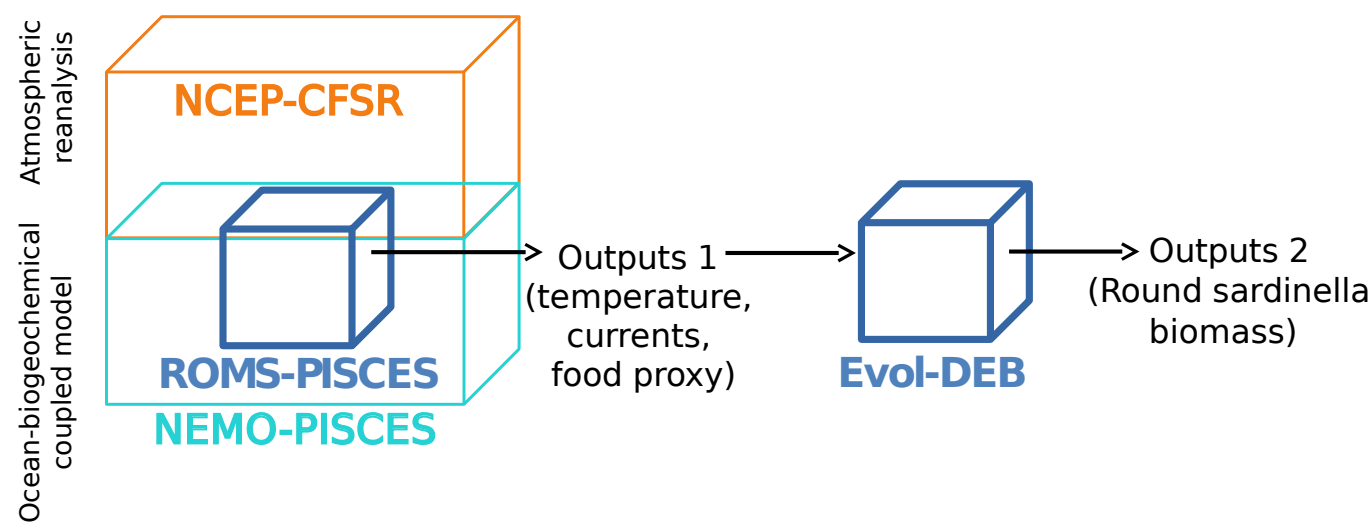

Figure 2: Modeling framework. The abbreviations used are: National Centers for Environmental Prediction (NCEP), Climate Forecast System Reanalysis (CFSR), Regional Oceanic Modeling System (ROMS), Pelagic Interaction Scheme for Carbon and Ecosystem Studies (PISCES), Nucleus for European Modelling of the Ocean (NEMO), and evolutionary individual-based model with dynamic energy budget (Evol-DEB) 
a)

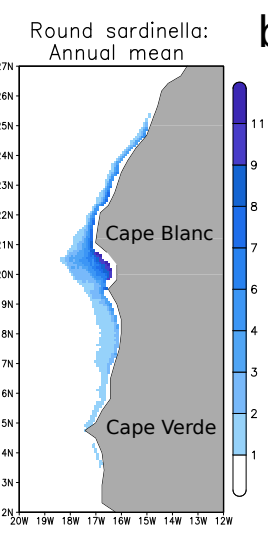

c)

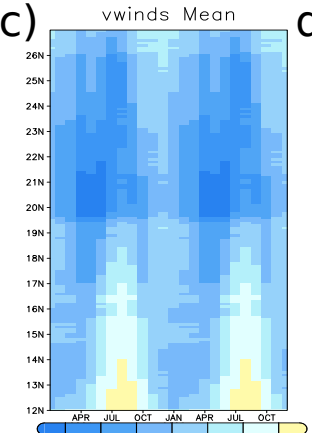

e)


b) Round sardinella:

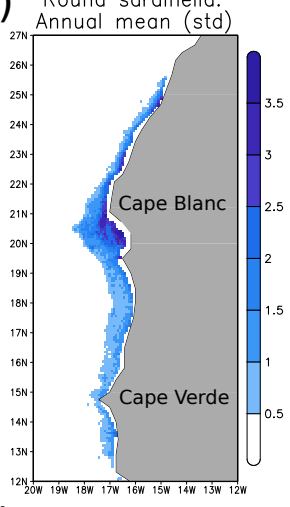

d)

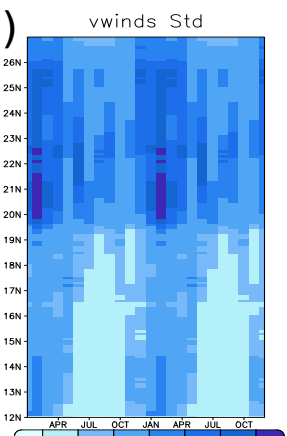

)

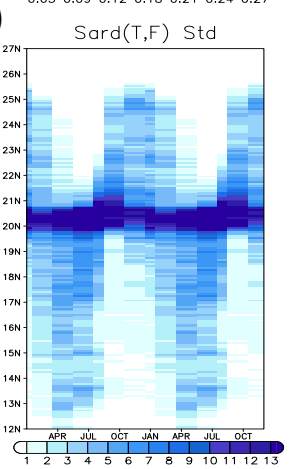

Figure 3: Annual mean and seasonal cycles from the modeling framework. In top panels the annual mean of round sardinella biomass (panel a), and the interannual variability of round sardinella biomass (in terms of standard deviation; panel b), from Evol-DEB. Units in tons $/ \mathrm{m} 2$. Central panels: Seasonal cycles (mean in panel c, negative southward, and variability, in terms of standard deviation, in panel d) of the meridional component of the wind stress (from ROMS-PISCES; units in $\mathrm{N} / \mathrm{m} 2$ ). Bottom panels: as panels c and d but for the simulated round sardinella biomass (from Evol-DEB; units in tons $/ \mathrm{m} 2$ ). In the case of the meridional wind stress, the fields are averaged from the coast to the isobath 1000 meters. 
along the northwest African coast). The associated standardized principal components (PC) show the time evolution of the scores of the EOFs, thus identifying the years in which these EOFs are manifest. The link between these EOFs (or round sardinella modes) and the climate was evaluated in terms of regression and composites maps. To analyze the link with the largescale environment (i.e., global climate), SST data from HadISST1 (Rayner et al., 2003), and global observed sea level pressure data (SLP) and surface winds from the NCEP Climate Forecast System Reanalysis (CFSR; Saha et al., 2010) were used. The HadISST dataset was also used to calculate the Niño 3.4 index (SST averages over the area $170-120^{\circ} \mathrm{W}, 5^{\circ} \mathrm{S}-5^{\circ} \mathrm{N}$ ), and the CFSR reanalysis was chosen to be consistent with the atmospheric conditions prescribed in the ROMS-PISCES simulation. Sea temperature and ocean currents averaged over the top $50 \mathrm{~m}$ of the water column (from ROMSPISCES) were used to characterize the local environmental variability (i.e., local climate). Please see the Table 1 for a summary of the data used in the present study. The statistical significance was assessed by a bootstrap re-sampling procedure with replacement. At the end of the study, a lead-lag correlation analysis has been applied for exploring the predictive potential of round sardinella distribution in the CCUS from equatorial Pacific SSTs. In that case, the non-parametric test described by Ebisuzaki (1997), and specially designed to avoid serial correlation, was used.

Table 1: Summary of the data used in the present study.

\begin{tabular}{c|c|c} 
Variable & Source & Reference \\
\hline \hline (Global) SST & HadISST & Rayner et al. (2003) \\
\hline (Global) SLP & CFSR & Saha et al. (2010) \\
\hline (Global) Surface winds & CFSR & Saha et al. (2010) \\
\hline Sea temperature & $R O M S-P I S C E S$ & Auger et al. (2015) \\
\hline Ocean currents & $R O M S-P I S C E S$ & Auger et al. (2015) \\
\hline Wind stress & ROMS-PISCES & Auger et al. (2015) \\
\hline Round sardinella biomass & Evol-DEB & Brochier et al. (2018)
\end{tabular}

A linear regression prediction model was also constructed in the present study to illustrate the potential of the results obtained for skillful prediction. This prediction model is based on the "leave one out" method (Wilks, 2011), 
which produces a forecast for each time $t$ (year) using only data at other times (years) distinct from $t$.

\section{Results}

\subsection{Anomalous migration further north of Cape Blanc}

The present modeling framework produces a coherent migration pattern of round sardinella population (Fig. 3e): to the south in spring reaching the Senegalese-Mauritanian waters in summer, and to the north in autumn, reaching the Saharan waters in winter (Corten et al., 2012). This migration pattern from Evol-DEB is associated with the atmospheric conditions imposed on ROMS-PISCES. Evidence from that fact is the consistency between the meridional wind stress (Vst, negative southward; see Fig. 3c) and the round sardinella biomass further north of Cape Blanc $\left(\sim 21^{\circ} \mathrm{N}\right)$, a region characterized by strong alongshore currents to the south, in the so-called Cape Blanc Transition Zone. Only in early winter, when the southward wind stress in this area weakens (Fig. 3c), a certain percentage of round sardinella (those with the strongest swimming capacity) reach the Saharan waters (Fig. 3e), where the high food availability contributes to relatively high HQI all year round (Brochier et al., 2018). Interestingly, this minimum of southward wind stress in winter coincides with the strongest variability of this variable off Cape Blanc (Fig. 3d) and, with increased variance in round sardinella biomass north of that cape (Fig. 3f). The variability is expressed here in terms of the standard deviation, representing the degree of deviation of each variable with respect to its corresponding seasonal cycles.

Hence, Fig. 3 points to the existence of year-to-year variability further north of Cape Blanc in both the environment and the round sardinella biomass. To assess the correlation between these variabilities, an EOF analysis was performed on the yearly Hovmöllers of round sardinella biomass anomaly along the coast, from $19^{\circ} \mathrm{N}$ to $26^{\circ} \mathrm{N}$, and for the January to March season. This season was selected in order to cover those months with the maximum variability in the alongshore wind stress (Vst; Fig. 3d). The Principal Component (hereinafter PC1) of the leading EOF mode, which explain $46 \%$ of the total variance, was then lag-regressed on the yearly Hovmöllers of round sardinella biomass (plotted from the previous July to the following June for a better comparison with the seasonal cycles; see Fig. 4a). A 
dipole structure, with negative anomalies off the Saharan coast and positive anomalies off Cape Blanc was obtained from early to late winter. This analysis indicates that anomalous meridional migration of round sardinella may play a key role in determining the biomass and distribution of round sardinella along the northwest African coast.

\subsection{Role played by the environment}

Firstly, the role of the environment in stimulating this leading mode of variability was investigated by analyzing an additional Evol-DEB simulation with climatological forcings obtained by averaging the ROMS-PISCES outputs for the entire period (1980-2009). That is, instead of forcing Evol-DEB with the varying environmental conditions from 1980 to 2009 (Inter experiment in Table 2), it was forced with the climatological averaged conditions in that period (Control experiment in Table 2). Therefore the interannual variability within the ROMS-PISCES outputs was removed such that this simulation may be interpreted as a control simulation for Evol-DEB. EOF analysis shows that the dipolar structure is missing in this control simulation (Fig. 4b), indicating that the response in the Inter experiment was forced by the environment.

Table 2: Overview of the set of Evol-DEB simulations run for the present study. Round sardinella dependence refers to those environmental parameters (Temperature, Food or both), from ROMS-PISCES, influencing the habitat quality of the species in Evol-DEB. Food contribution is quantified through a proxy defined as the sum of the biomass in the four PISCES plankton compartments (please see Brochier et al. 2018 for details).

\begin{tabular}{c|cc} 
Experiment & ROMS-PISCES forcing & round sardinella dependence \\
\hline Inter & $1980-2009$ & $\mathrm{~T}, \mathrm{~F}$ \\
Control & $(1980-2009)_{\text {avg }}$ & $\mathrm{T}, \mathrm{F}$ \\
Inter T & $1980-2009$ & $\mathrm{~T}$ \\
Inter F & $1980-2009$ & $\mathrm{~F}$
\end{tabular}

\subsection{El Niño emerges as a potential forcing}

Considering the important role of SSTs in the global climate teleconnections, next the PC1 from the Inter experiment was regressed on the global 
Table 3: Linear correlations among the distinct PC1 obtained in the set of simulations recapitulated in Table 2 .

\begin{tabular}{c|ccc} 
Correlation & $\mathrm{PC} 1($ Control $)$ & $\mathrm{PC} 1($ Inter T) & $\mathrm{PC} 1($ Inter F) \\
\hline $\mathrm{PC} 1$ (Inter $)$ & 0.02 & 0.88 & 0.41
\end{tabular}

SSTs of the same season. A noticeably clear and significant ENSO pattern emerged in the tropical Pacific (Fig. 5a). The same ENSO structure appeared when just an index based on the averaged accumulation of round sardinella off Cape Blanc was projected onto the SSTs (not shown). The question emerging therefore is whether this anomalous response of round sardinella in northwest Africa (the aforementioned dipolar structure) is caused by ENSO or if it is a statistical artifact.

Before exploring the dynamical mechanisms linking ENSO and round sardinella spatio-temporal variability, the environmental response to ENSO in northwest Africa that causes the anomalous distribution of modeled round sardinella biomass along the coast was investigated. To address this question, recall that both temperature and food distribution influence the HQI in the previously described Evol-DEB simulations (Inter Experiment \& Control Experiment), as these follow the more realistic configuration according to Brochier et al. (2018). Assuming that the sardinella dependence on their habitat quality is based only on the food availability (Inter F experiment in Table 2) leads to the disappearance of the previously analyzed dipolar structure (Fig. 6c). However, this is not the case when the HQI is based only on sea temperature (Fig. 6a). Therefore it could be concluded that the dipolar structure identified in Fig. 4a is associated with the round sardinella's dependence on water temperature as represented in the model. Please note that this does not mean that round sardinella only follows the variability of the water temperature. Others factors, such as alongshore currents, could also play a major role in altering the round sardinella variability. However, this major role would only emerge when round sardinella migrates towards areas with optimal temperature conditions. If this dependence on the temperature is removed, the effect of ENSO on round sardinella also disappears. This effect of temperature on the teleconnection is reinforced by the correlations among the leading principal components of round sardinella's biomass in the 

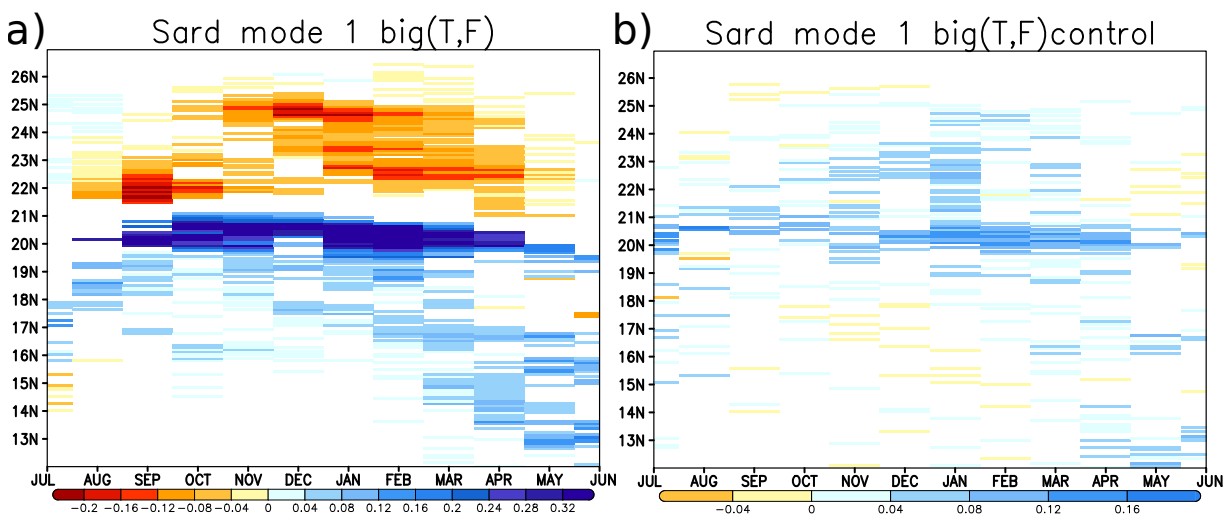

Figure 4: Round sardinella EOF: a mode forced by the environment. Leading EOF of the anomalous sardinella biomass (calculated from $19^{\circ} \mathrm{N}$ to $26^{\circ} \mathrm{N}$ and for the JFM season; units in tons/m2 per std in the PC1) obtained in: a) the Inter experiment and b) the Control experiment. Shading areas represent the $90 \%$ significant response according to a bootstrap technique with replacement. Please note that blue and red colors indicate positive and negative anomalies of biomass respectively.

different simulations (see Table 3). Furthermore, the regression maps of the leading PCs on global SSTs showed that the ENSO pattern persists when the round sardinella dependence on food is removed (Inter T experiment; see Fig. 6b), but disappears when the round sardinella dependence on temperature is removed (Inter F experiment; see Fig. 6d).

There is still a remaining aspect to fully characterize the ENSO-round sardinella teleconnection: its linearity in relation to the ENSO phase. In particular, the question emerging is whether the identified ENSO signal is caused by the influence of both warm (El Niño) and cold (La Niña) ENSO phases. Comparing the evolution of the Niño 3.4 index and the standardized round sardinella PC1 (Inter Experiment) revealed that the three highest values of PC1 coincide with three $(1988,1998,2003)$ of the four highest values of the Niño 3.4 index. Nevertheless, there is an absence of coincidence in time between the negative values of the Niño 3.4 index and the peaks of the round sardinella PC1. This appears more clearly when comparing the negative composite patterns (those years in which the index is below - 1 standard deviation) of SSTs for the Niño 3.4 index and the round sardinella PC1 (Supplementary material; Fig. S1): this indicates that a negative occurrence of the round sardinella mode is more related to the NAO than to the Pacific 

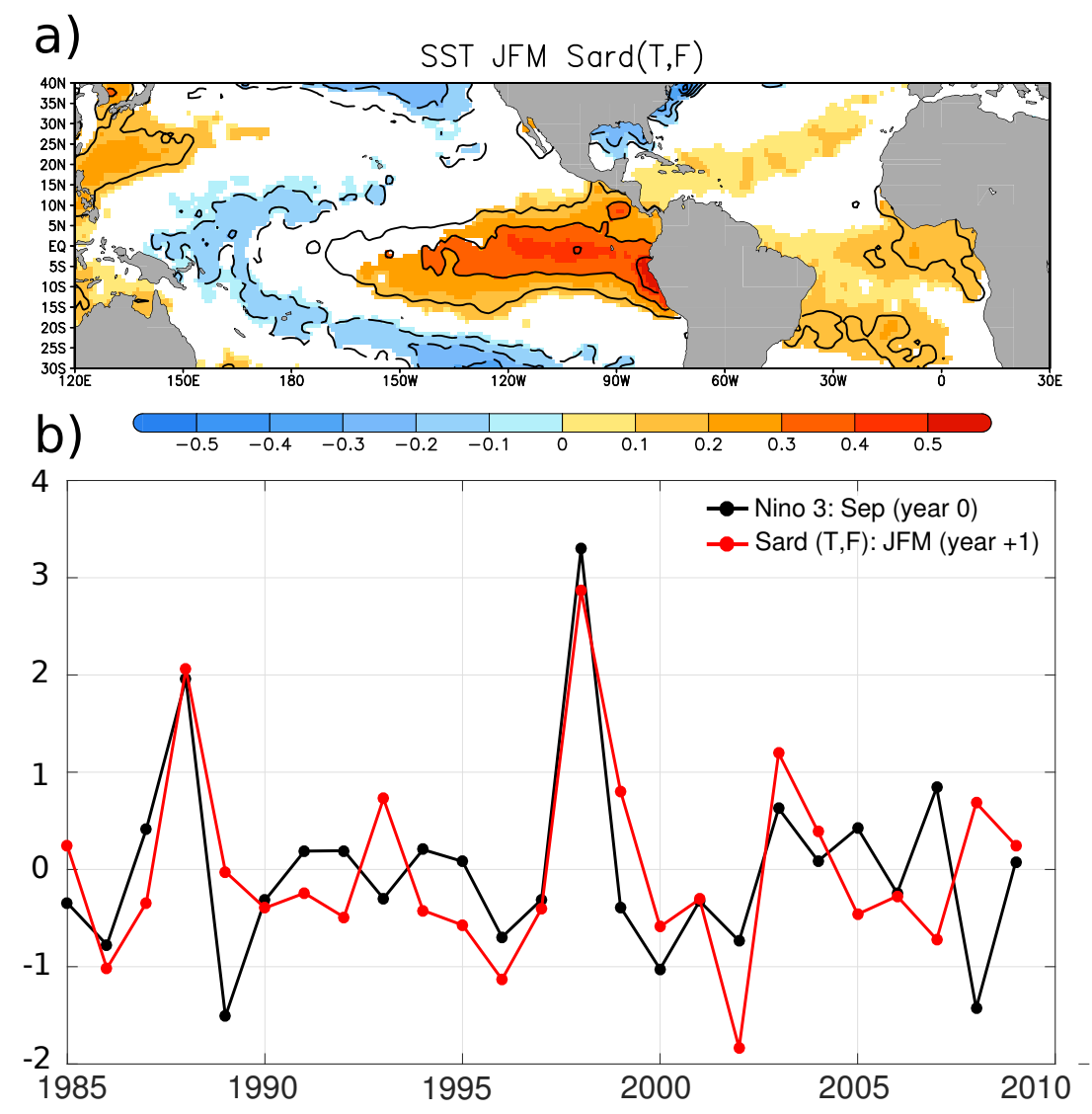

Figure 5: Round sardinella EOF: a mode forced ENSO. a) Regression map of the round sardinella mode of biomass on anomalous SSTs (units in degrees per std in the PC1); shading areas represent the $90 \%$ significant response according to a bootstrap technique with replacement. b) standardized PC1 of the round sardinella mode (red line) and the standardized Niño 3.4 index in the previous September (black line). 


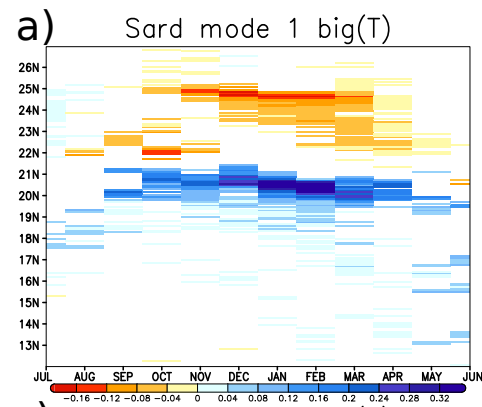

b)

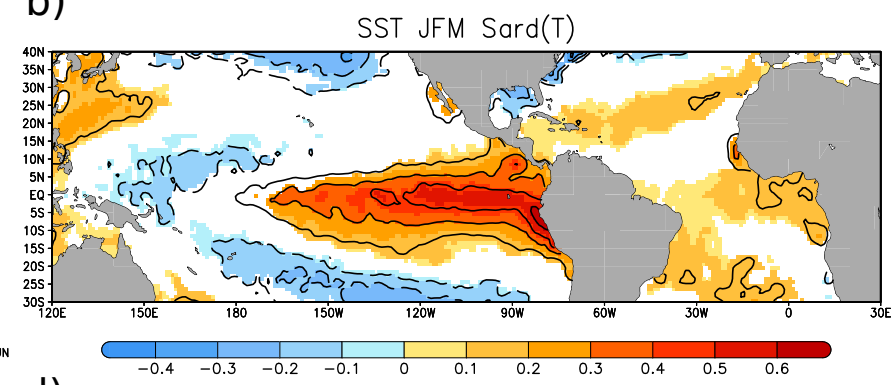

C) $\quad$ Sard mode $1 \mathrm{big}(F)$

d)
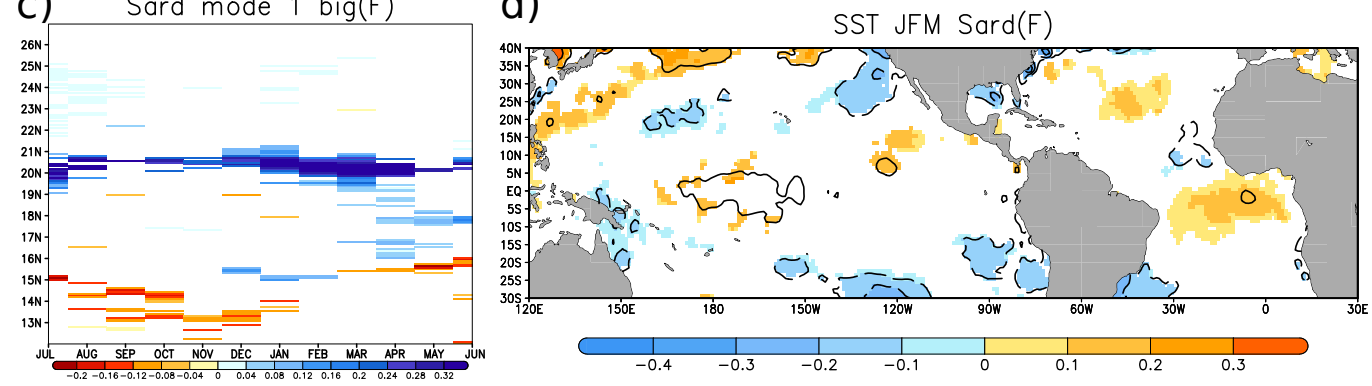

Figure 6: Round sardinella EOF: a mode highlighting the role of temperature. a) leading EOF of anomalous sardinella biomass for the Inter T Experiment, b) SST regression for the Inter T Experiment, c) leading EOF of anomalous sardinella biomass for the Inter F Experiment, d) SST regression for the Inter F Experiment. Shading areas represent the $90 \%$ significant response according to a bootstrap technique with replacement. 
SSTs. Thus, the ENSO-round sardinella link found in the described modeling framework is only triggered by warm ENSO phases (El Niño).

\subsection{Dynamical mechanisms}

To address the dynamical explanations supporting this influence of El Niño episodes on the modeled round sardinella biomass, early winter (from November to January) and late winter (from February to March) were separated based on: 1) the different evolution of El Niño episodes and their related responses in the TNA, and 2) the very different feature of round sardinella migrations along the northwest African coast before and after January. Regarding the former, the response to ENSO in early winter is characterized by anomalous horizontal and vertical flows in the western TNA (Wang, 2002) and by an East Atlantic (EA) like pattern further north over the North Atlantic (King et al., 2018). From January onwards, an atmospheric Rossby wavetrain forced from the tropical Pacific crosses the North Pacific-American region and reaches the TNA (Enfield and Mayer, 1997). This response, together with the documented ENSO influence on the Walker and Atlantic Hadley circulation cells (Wang, 2004), explains the ENSO-TNA teleconnection in late winter. Regarding the round sardinella migrations along the northwest African coast, remarkable differences are also identified between early and late winter. Before January, round sardinella are normally moving northward to reach the Saharan waters (see Fig. 3e), where there is high food availability resulting in high HQI (Brochier et al., 2018). After January, however, round sardinella begin a southward migration. The underlying reasons include the declining food production when upwelling off Cap Blanc retracts to very coastal waters, and the drop in water temperature to values below the species tolerance. Furthermore, it is worth reminding that a natural instinct of round sardinella to search its natal homing temperature is implemented in Evol-DEB. Thus, as both the upwelling intensity and the water temperature could be altered by the El Niño influence in the study region, a related response in round sardinella is expected.

\subsubsection{Early-winter}

In early-winter (Fig. 7a), a marked El Niño pattern is identified in those years in which the anomalous round sardinella mode (Fig. 6a) is manifested. A weakening of the trade winds has been identified in the western TNA, in 
agreement with the documented response to ENSO (Wang, 2002). The resultant anomalous northward winds turn right at approximately $25-30^{\circ} \mathrm{N}$. This deflection is explained by the EA-like pattern found over the North Atlantic and is consistent with the most recent literature (King et al., 2018). Consequently, an anomalous increase of the subtropical winds is detected to the east that reaches the African continent. For illustrative purposes, the significant response of the surface wind (black vectors in Fig. 7a) is calculated with respect to the zonal component in Nov-Jan. In the ROMS-PISCES simulation, this global signal is associated with a significant increase of the zonal wind stress to the east (black vectors in Figs. 8a-b) and, even more important for this case, with an anomalous increase of the alongshore currents to the south (shaded areas in Fig. 8b). Note that this enhancement of the alongshore currents is particularly intense off Cape Bojador and Cape Blanc, although it is not associated with significant upwelling-favorable wind anomalies. Off Cape Blanc, it appears to coincide with the anomalous accumulation of round sardinella biomass simulated by Evol-DEB (Fig. 6a). Thus, the response to El Niño drives anomalous southward alongshore currents in early winter, along the Cape Blanc Frontal Zone, that counters the normal northward migration of round sardinella. As a consequence, an anomalous increase (decrease) of biomass emerges at $\sim 20-21^{\circ} \mathrm{N}\left(\sim 24-25^{\circ} \mathrm{N}\right)$.

\subsubsection{Later-winter}

In late winter, the round sardinella mode is related to northward wind anomalies in the eastern part of the TNA that occur after the peak of El Niño episodes and which are particularly intense along the northwest African coast (the significant signal of the meridional component is highlighted as black vectors in Fig. 7b). The weakened Azores high identified in Fig. 7b is in agreement with the documented late winter influence of ENSO caused by the thermally-driven direct circulation (Wang, 2004) and Rossby wave activity (Enfield and Mayer, 1997). The anomalous SST pattern identified here is also as expected (Ham et al., 2014). The resultant alongshore winds in northwest Africa weakens the upwelling due to a reduction of the Ekman transport and hence, an intense and significant anomalous warming is detected along the coast. The ROMS-PISCES model reproduces the anomalous warming along the coast as a consequence of the attenuated coastal upwelling (Fig. 8c) and simulates northward coastal current anomalies (Fig. 8d). 

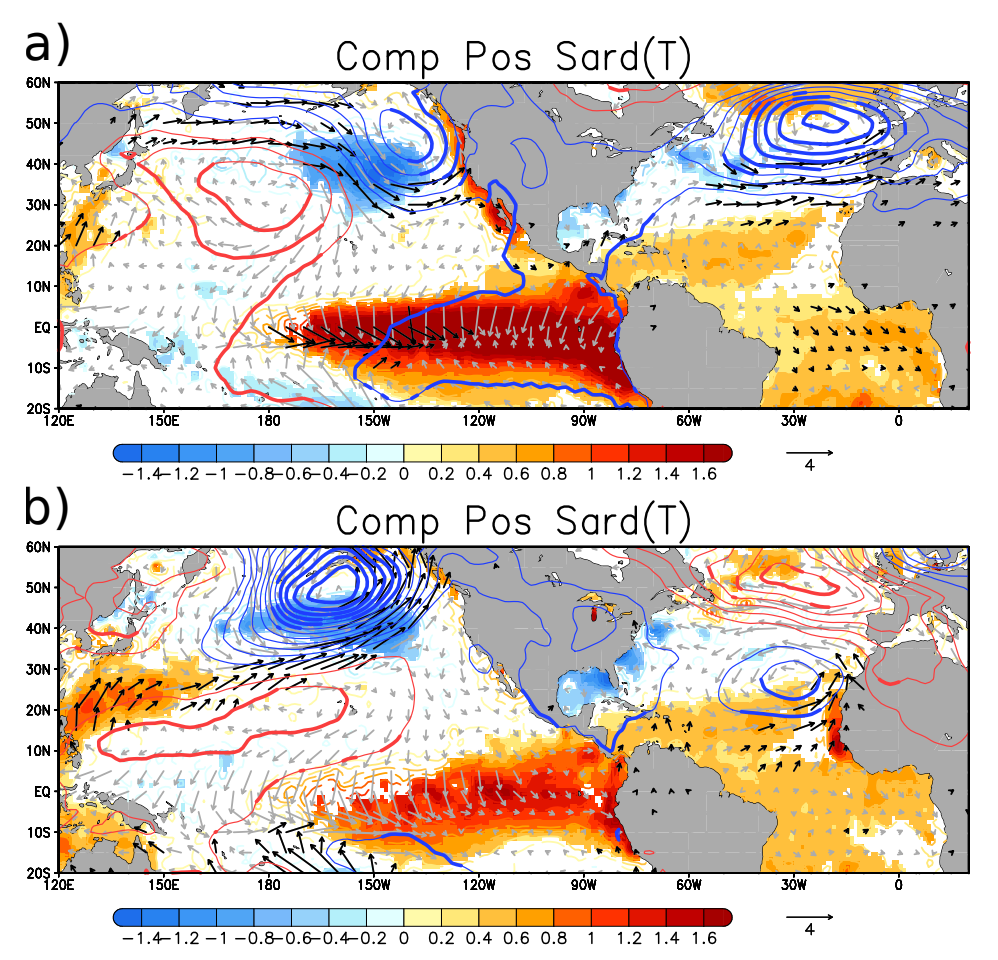

Figure 7: Global signature of the round sardinella mode. a) positive composite maps in early winter based on the standardized PC1 of the anomalous sardinella mode (years above 1 standard deviation), b) as in a) but for late winter. In both cases the fields plotted are: anomalous SST (shaded the significant response; units in degrees), anomalous SLP (contoured; thick contoured the significant response), and anomalous surface wind (grey vectors; units in $\mathrm{m} / \mathrm{s}$ ). Significance at the $90 \%$ level based on a bootstrap technique with replacement. 



Figure 8: Local signature of of the round sardinella mode (ROMS-PISCES). Upper panels corresponds to the composites maps in early winter (Nov-Jan) and bottom panels to the composites maps in late winter (Feb-Mar). Left panels show the anomalous temperature in the top 50 meters of the water column (shaded the significant response; units in degrees). In the right panels the anomalous meridional currents of the top 50 meters of the water column (shaded the significant response, units in $10 \mathrm{x} \mathrm{m} / \mathrm{s}$ ). The anomalous wind stress (vectors; units in $\mathrm{N} / \mathrm{m} 2$ ) are shown on all panels. Only the water surfaces with less than 1000 meters depth are plotted due to these waters house the vast majority of round sardinella. The significant response in the zonal (meridional) anomalous wind stress is highlighted for early (late) winter with black vectors. Significance at the $90 \%$ level based on a bootstrap technique with replacement. Large pointing-arrows indicate the migration pattern of the species in early and late winter according to the seasonal cycle of biomass. 
To understand the round sardinella response, it is important to realize that although the presence of the species has been reported in a very large range of temperatures, from $\sim 10^{\circ} \mathrm{C}$ in the Mediterranean Sea (Tsikliras and Antonopoulou, 2006) up to $29^{\circ} \mathrm{C}$ in Senegal (Marchal, 1991), the highest biomass in northwest Africa has been detected for a range of SSTs between $21^{\circ} \mathrm{C}$ and $25^{\circ} \mathrm{C}$ (Diankha et al., 2015). Thus, waters excessively cold (below $19^{\circ} \mathrm{C}$ ) or excessively warm (above $26-27^{\circ} \mathrm{C}$ ) host low round sardinella biomass. This feature is included in Evol-DEB by a correction factor applied to all the energy fluxes between the model compartments. Thus, one can understand why in late winter, under normal conditions, the drop of water temperatures off the Saharan bank to values below $19^{\circ} \mathrm{C}$ contributes to a southward migration (favored by the climatological southward currents) of round sardinella.

In this context, the anomalous warming generated by El Niño in late winter off the African coast (Fig. 8c) increases the absolute temperature of the water column off Cape Blanc to around $20^{\circ} \mathrm{C}$, significantly warmer than the normal $\sim 18^{\circ} \mathrm{C}$ there at that time of the year (see also Fig. S2 in Supplementary material). This fact, together with the reduced passive advection of round sardinella due to the anomalous weakening of the southward currents south of Cape Blanc during El Niño years (Fig. 8d), explains how the anomalous accumulation of biomass at $20-21^{\circ} \mathrm{N}$ latitude identified in EvolDeb in association with the leading EOF mode (Fig. 6a) persists until well into the spring season. However, the persistence of negative biomass anomalies further north of Cape Blanc seems to be a reminiscent effect of the fewer individuals who reached the Saharan waters at the beginning of the winter season. The slight positive biomass anomalies detected between $13^{\circ} \mathrm{N}$ and $19^{\circ} \mathrm{N}$ (Fig. 4a) in late winter might reflect the response of round sardinella to the warmer and more favorable water temperature conditions along the Mauritanian-Senegalese coast as a consequence of the reduced upwelling.

\subsection{Potential predictability of round sardinella population biomass}

One of the main contributions of this work is that it provides the basis for the development of a future seasonal forecasting tool of round sardinella latitudinal distribution along northwest Africa based on El Niño-related SSTs, which can be observed from the space. In particular, high lagged correlations between the round sardinella mode in winter (see Fig. 6a) and the Niño 3 


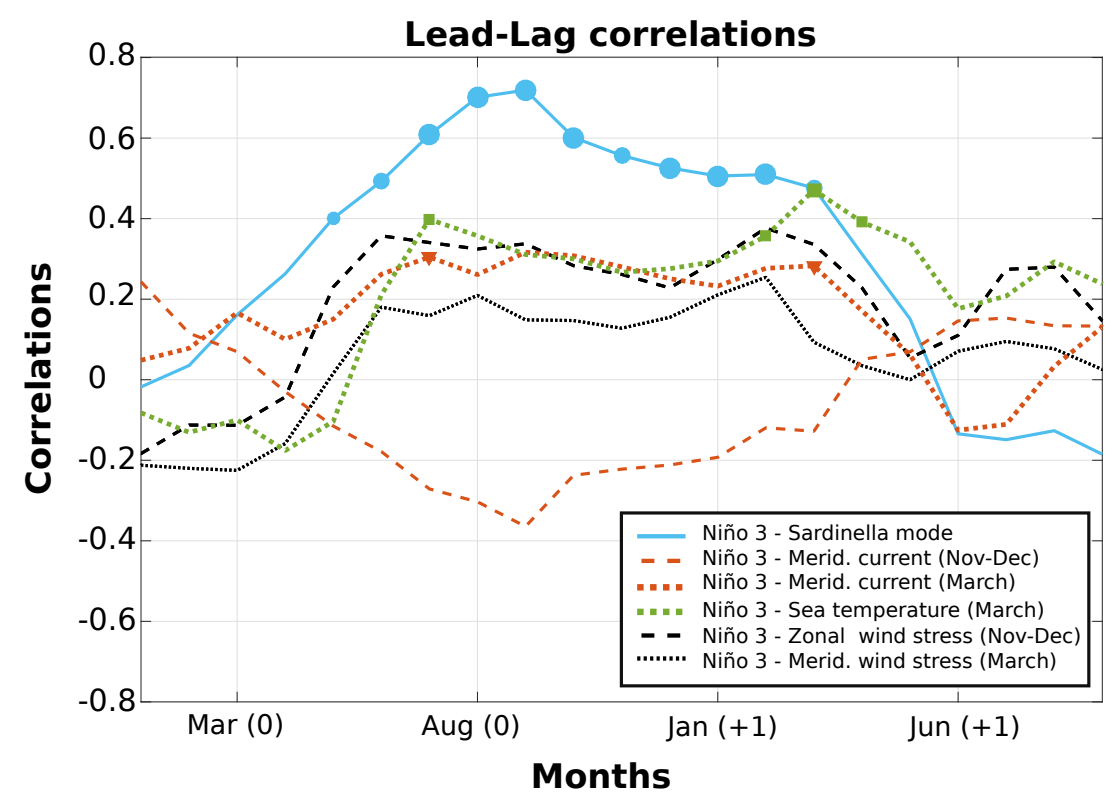

Figure 9: Lead-lag correlations. Blue solid line shows the linear correlation between the Niño 3 index at different lags and the leading sardinella mode (i.e., the corresponding PC) in JFM (year +1 ; see Fig. 6a). The same correlations with the Niño 3 index are shown for: 1) the meridional current (top $50 \mathrm{~m}$ of the water column) off Cape Blanc in Nov-Dec (dashed brown line) and March (dotted brown line), and 2) the water temperature (top 50m of the water column) off Cape Blanc in March (green dotted line). The region off Cape Blanc is defined as the area within the red square indicated in Fig. 8b. Large, medium and small sized symbols represent correlations at the $99 \%, 95 \%$ and $90 \%$ confidence level respectively according to Ebisuzaki (1997). Black dashed (dotted) line shows the correlation between the leading round sardinella mode and the zonal (meridional) wind stress averaged within the green boxes of Fig. 8.

index suggest the potential for skillful prediction (see blue line in Fig. 9). The El Niño-round sardinella link appears stronger with the eastern tropical Pacific than with the central tropical Pacific (Supplementary material; Fig. S3), which is consistent with the available literature related to the ENSOTNA teleconnection (Taschetto et al., 2016).

A linear regression prediction model based on the "leave one out" method (Wilks, 2011) has been constructed to predict, for the two strongest Eastern El Niño episodes of the simulated period (1987/88 and 1997/98), the anomalous distribution of round sardinella from El Niño 3 SSTs in the previous September. The resultant predictions and the corresponding patterns esti- 
mated by Evol-DEB are shown in Figure 10. One could reasonably think that our prediction skill, based on the leading EOF of round sardinella biomass in winter, should be almost completely dependent on the information coming from the specific episodes to be predicted, as they correspond to extreme values of the aforementioned EOF. However, if so, the forecast skill assessed with our cross-validation method should be close to zero. As shown in Fig. 10a-d, this is not the case: the anomalous SSTs in the Niño 3 region in September (i.e., September 1987 and September 1997, respectively) are enough to predict realistically the anomalous distribution of round sardinella in the following winter and spring along the northwest African coast. Although robust, this predictive skill seems to be only valid for eastern (and particularly strong) El Niño years, as appreciated in the comparison between the modeled and the predicted evolution of round sardinella population biomass in a particular location (Cape Blanc; see bottom panel in Fig. 10e).

\section{Summary and discussions}

The present study provides, for the first time, a consistent mechanism explaining how a remote climatic phenomenon (El Niño, understood as the ENSO warm phases) is able to alter the latitudinal migration pattern of Sardinella aurita (or round sardinella) in the narrow coastal band along northwest Africa. This has been possible through an innovative modeling strategy specifically designed to explore potential environmental drivers of spatio-temporal population variability of this species in the region. This modeling framework has been previously validated in the study region and highlighted the strong effect that the local environment may play on the distribution of round sardinella along this coast (Brochier et al., 2018).

Modeling results point out that the round sardinella response to El Niño is an anomalous migration pattern of this species during boreal winter between the Mauritanian and the Saharan waters. As a consequence, the model simulates an anomalous increase (decrease) of round sardinella biomass off the Cape Blanc (Saharan coast) during El Niño years. Distinct bio-physical mechanisms take place in early and late winter to sustain this modeled marine ecological response to El Niño (if needed, see scheme in Fig. S4 of Supplementary material). This difference between early and late winter is not really surprising, as 1) the climatological responses to El Niño evolve 

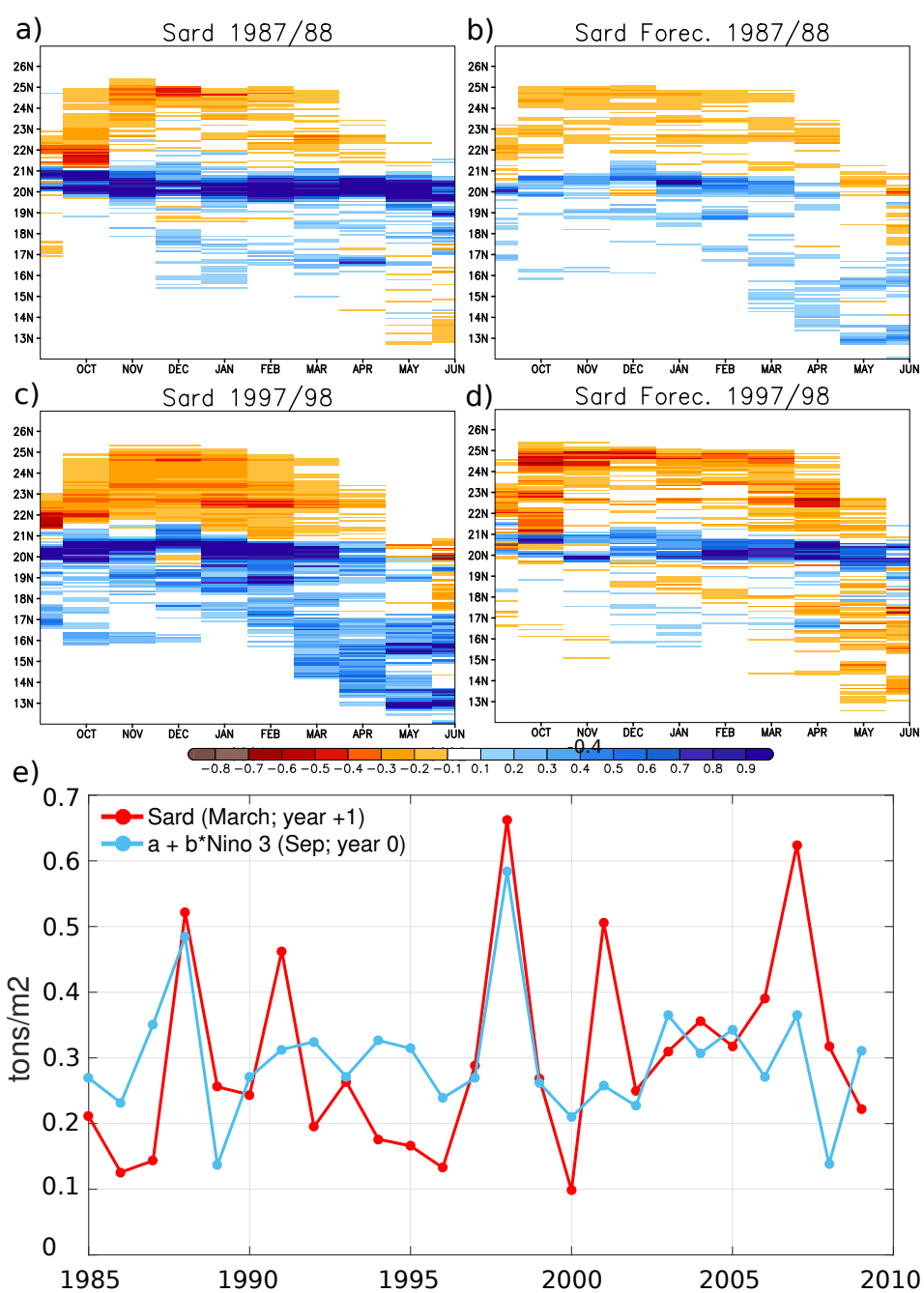

Figure 10: Potential predictability. Round sardinella biomass anomaly from Evol$D E B$ in: a) $1987 / 1988$ and c) $1997 / 1998$. Prediction of the modeled round sardinella biomass anomaly (from El Niño 3 SSTs in the previous September) in: b) 1987/1988 and d) $1997 / 1998$. Units in tons $/ \mathrm{m} 2$. In the bottom panel the time evolution of the round sardinella biomass in March off Cape Blanc from Evol-DEB (red line) and its prediction from El Niño 3 SSTs in the previous September (blue line). 
over time along the winter months and 2) the dynamical feature of round sardinella off northwest Africa is completely different before and after January, being characterized by a northward migration (searching the Saharan bank) in the former case, but by a southward migration, avoiding the cold conditions in the Saharan waters from January onwards, in the latter case. Accordingly, the specific responses to El Niño identified in the described modeling framework and the proposed mechanisms in each sub-season are:

- In early winter (November-January), a weakened northward migration of round sardinella. This signal could be explained by an anomalous enhancement of the alongshore currents to the south, off the Cape Blanc region, due to the El Niño influence.

- In late winter (February-March), an anomalous accumulation of round sardinella off Cape Blanc, the underlying mechanism being twofold: 1) through a weakening of the alongshore currents to the south (reducing the passive advection component of the southward migrations of round sardinella) and 2) through an anomalous warming of the surface ocean due to a reduction of the coastal upwelling (which improve the habitat conditions of round sardinella).

Summarizing, the El Niño-round sardinella teleconnection simulated here is mainly explained by the modulating role that the anomalous alongshore currents forced by El Niño in the Cape Blanc Frontal Zone exerts on the normal migration of this species when it avoids water temperatures out of the species tolerance and when it follows temperatures close to its natal homing conditions. Thus, a general conclusion from the results of this study is that a realistic response to El Niño in both, sea temperature and coastal currents, is crucial to produce the teleconnection proposed. From a large-scale perspective, there is an extensive literature explaining the dynamical aspects associated with the ENSO-TNA teleconnection and it is not a major goal of this work to explain this in depth. However, it is worth mentioning how the mechanisms presented here are consistent with those accepted by the climate community (Enfield and Mayer, 1997, Wang, 2002, 2004, Ham et al., 2014, King et al., 2018), reinforcing therefore the robustness of the El Niño-round sardinella teleconnection.

Although a full validation of the El Niño-round sardinella teleconnection is an extremely challenging issue due to the scarcity of reliable data on the 
time varying distribution and abundance fish population, the modeling approach presented here seems to be able to simulate a robust ENSO response of the environmental conditions off Cape Blanc in winter, closely related to the ENSO induced effects in round sardinella biomass (Supplementary material; Fig. S5). In this respect, it is worth mentioning that the water temperature and ocean current responses described here are consistent with those identified in February-March 1998 after the peak of one of the strongest El Niño episodes of the last decades (Zeeberg et al., 2008). This reinforces the theory of an influence of El Niño on the hydrodynamic conditions along the Mauritanian-Saharan coast. This fact, together with the validated skill of the modeling strategy used to simulate realistic responses of round sardinella to the local environment (Brochier et al., 2018), substantiates the findings of this work.

In contrast to the major role that food availability plays for determining sardine and anchovy abundance in the northern part of the CCUS (SánchezGarrido et al., 2019), the present analyses indicate that the alteration of the variability in nutrient abundance associated with El Niño seems to play a minor role for the El Niño-round sardinella teleconnection. This is actually consistent with previous works which suggest that the currents and the water temperature are the main environmental variables influencing the round sardinella variability in the southern part of this upwelling system (Zeeberg et al., 2008, Bacha et al., 2017). However, other studies argue for a weaker (Roy and Reason, 2001, Arístegui et al., 2006) or an absent (Cropper et al., 2014, Oettli et al., 2016, Gómez-Letona et al., 2017) link between ENSO and the northwest African environmental conditions. This apparent inconsistency can be explained by diverse causes, such as 1) the distinct manifestations of the CCUS variability to the methodology applied (Benazzouz et al., 2014) or 2) the fact that in this study, the degrees of freedom of the entire spatiotemporal variability of round sardinella were reduced by using the latitude as a measure of spatial location (by averaging the biomass in longitude over the continental shelf) and by focusing the analysis on a particular mode of variability. All this could have contributed to a more efficient identification of the El Niño related response in this study.

Furthermore, it should not be ruled out that round sardinella could act as an ecological integrator of El Niño influence on northwest Africa, showing even higher correlations than those obtained through the use of other 
environmental fields (e.g., water temperature, currents, or Chl-a), which intuitively should be more directly influenced by a remote climate forcing (Di Lorenzo and Ohman, 2013). Indeed, the round sardinella mode analyzed here presents higher correlations with the Niño index than with the local environment (wind stress, meridional current and sea temperature) off northwest Africa (Fig. 9). This striking feature had been already found for other ecological impacts of ENSO (Capa-Morocho et al., 2014, Diouf et al., 2017). The present study suggests a capacity of round sardinella to integrate the non-linearities among the climate variables in a unique mode of biomass variability.

We are aware of the intrinsic limitations of the modeling approach used in this study, and we do not expect a perfect match between the real (ideally observed) and the simulated responses of round sardinella to the environment. Nevertheless, this approach provides a highly valuable measure of how the spatio-temporal variability of round sardinella reacts to actual climate forcings (Brochier et al., 2018). Thus, we believe that this study represents a valuable step forward in relation to how the global climate can alter local responses in marine ecosystems. Furthermore, given that enhanced global responses to ENSO are expected under a warmer climate (Frauen et al., 2014), the El Niño-round sardinella teleconnection might enhance within the next decades. This and other related questions should be further analyzed in future works.

\section{Acknowledgments}

The authors thank Davide Zanchettin and Patrice Brehmer for their useful comments and support during the development of this study. This work was funded by the european PREFACE project (No. 603521, Enhancing prediction of tropical Atlantic climate and its impacts http://preface.b.uib.no) and by the european TRIATLAS project (No. 817578, South and tropical Atlantic climate-based marine ecosystem prediction for sustainable management). Additional support during the writing phase (for P.A. Auger) was provided by the Instituto Milenio de Oceanografía (IMO-Chile), funded by the Iniciativa Científica Milenio (ICM-Chile). 


\section{References}

Arístegui, J., Alvarez-Salgado, X. A., Barton, E. D., Figueiras, F. G., Hernandez-Leon, S., Roy, C., Santos, A., 2006. Oceanography and fisheries of the canary current/iberian region of the eastern north atlantic (18a, e). The global coastal ocean: Interdisciplinary regional studies and syntheses 14,879 .

Auger, P.-A., Gorgues, T., Machu, E., Aumont, O., Brehmer, P., Nov. 2016. [DATASET] What drives the spatial variability of primary productivity and matter fluxes in the north-west African upwelling system? A modelling approach. Biogeosciences 13, 6419-6440.

Auger, P. A., Machu, E., Gorgues, T., Grima, N., Waeles, M., 2015. Comparative study of potential transfer of natural and anthropogenic cadmium to plankton communities in the north-west african upwelling. Science of the Total Environment 505, 870-888.

Aumont, O., Bopp, L., Jun. 2006. Globalizing results from ocean in situ iron fertilization studies. Global Biogeochemical Cycles 20, GB2017.

Aumont, O., Maier-Reimer, E., Blain, S., Monfray, P., Jun. 2003. An ecosystem model of the global ocean including $\mathrm{Fe}$, Si, P colimitations. Global Biogeochemical Cycles 17, 29-1.

Bacha, M., Jeyid, M. A., Vantrepotte, V., Dessailly, D., Amara, R., 2017. Environmental effects on the spatio-temporal patterns of abundance and distribution of sardina pilchardus and sardinella off the mauritanian coast (north-west africa). Fisheries Oceanography 26 (3), 282-298.

Báez, J., Santamaría, M., García, A., Gonzalez, J., Hernández, E., FerriYáñez, F., 2019. Influence of the arctic oscillations on the sardine off northwest africa during the period 1976-1996. VIE ET MILIEU-LIFE AND ENVIRONMENT 69 (1), 71-77.

Bakun, A., 1990. Global climate change and intensification of coastal ocean upwelling. Science 247 (4939), 198-201.

Bakun, A., Black, B. A., Bograd, S. J., Garcia-Reyes, M., Miller, A. J., Rykaczewski, R. R., Sydeman, W. J., 2015. Anticipated effects of climate 
change on coastal upwelling ecosystems. Current Climate Change Reports $1(2), 85-93$.

Barton, E., Arıstegui, J., Tett, P., Cantón, M., Garcı-Braun, J., HernándezLeón, S., Nykjaer, L., Almeida, C., Almunia, J., Ballesteros, S., et al., 1998. The transition zone of the canary current upwelling region. Progress in Oceanography 41 (4), 455-504.

Benazzouz, A., Mordane, S., Orbi, A., Chagdali, M., Hilmi, K., Atillah, A., Pelegrí, J. L., Hervé, D., 2014. An improved coastal upwelling index from sea surface temperature using satellite-based approach-the case of the canary current upwelling system. Continental Shelf Research 81, 38-54.

Bez, N., Braham, C.-B., 2014. Indicator variables for a robust estimation of an acoustic index of abundance. Canadian journal of fisheries and aquatic sciences 71 (5), 709-718.

Binet, D., 1988. Rôle possible d'une intensification des alizés sur le changement de répartition des sardines et sardinelles le long de la côte ouest africaine. Aquatic living resources 1 (2), 115-132.

Boëly, T., Chabanne, J., Fréon, P., Stéquert, B., 1978. Cycle sexuel et migrations de sardinella aurita sur le plateau ouest-africain des iles bissagos a la mauritanie. In: Symp. sur le courant des Canaries: upwelling et resources vivantes. Las Palmas. No. 92. pp. 1-12.

Braham, C.-B., Fréon, P., Laurec, A., Demarcq, H., Bez, N., 2014. New insights in the spatial dynamics of sardinella stocks off mauritania (northwest africa) based on logbook data analysis. Fisheries Research 154, 195204.

Brochier, T., Auger, P.-A., Pecquerie, L., Machu, E., Capet, X., Thiaw, M., Mbaye, B. C., Braham, C.-B., Ettahiri, O., Charouki, N., et al., 2018. [DATASET] Complex small pelagic fish population patterns arising from individual behavioral responses to their environment. Progress in Oceanography $164,12-27$.

Brochier, T., Echevin, V., Tam, J., Chaigneau, A., Goubanova, K., Bertrand, A., 2013. Climate change scenarios experiments predict a future reduction in small pelagic fish recruitment in the humboldt current system. Global change biology 19 (6), 1841-1853. 
Capa-Morocho, M., Rodríguez-Fonseca, B., Ruiz-Ramos, M., 2014. Crop yield as a bioclimatic index of el niño impact in europe: Crop forecast implications. Agricultural and forest meteorology 198, 42-52.

Carr, M.-E., Kearns, E. J., Nov. 2003. Production regimes in four Eastern Boundary Current systems. Deep Sea Research Part II: Topical Studies in Oceanography 50, 3199-3221.

Chavez, F. P., Messié, M., 2009. A comparison of eastern boundary upwelling ecosystems. Progress in Oceanography 83 (1-4), 80-96.

Corten, A., Braham, C.-B., Sadegh, A. S., 2017. The development of a fishmeal industry in mauritania and its impact on the regional stocks of sardinella and other small pelagics in northwest africa. Fisheries research 186 , 328-336.

Corten, A., Mendy, A., Diop, H., 2012. La sardinelle de lafrique du nordouest: Pêches, évaluation des stocks et la gestion. Sub-Regional Fisheries Commission (SRFC), Dakar.

Cropper, T. E., Hanna, E., Bigg, G. R., 2014. Spatial and temporal seasonal trends in coastal upwelling off northwest africa, 1981-2012. Deep Sea Research Part I: Oceanographic Research Papers 86, 94-111.

Czaja, A., van der Vaart, P., Marshall, J., Nov. 2002. A Diagnostic Study of the Role of Remote Forcing in Tropical Atlantic Variability. Journal of Climate 15, 3280-3290.

Di Lorenzo, E., Ohman, M. D., 2013. A double-integration hypothesis to explain ocean ecosystem response to climate forcing. Proceedings of the National Academy of Sciences 110 (7), 2496-2499. URL http://www.pnas.org/content/110/7/2496

Diankha, O., Thiaw, M., Sow, B. A., Brochier, T., GAyE, A. T., Brehmer, P., 2015. Round sardinella (sardinella aurita) and anchovy (engraulis encrasicolus) abundance as related to temperature in the senegalese waters. Thalassas 31 (2), 9-17.

Diouf, I., Rodriguez-Fonseca, B., Deme, A., Caminade, C., Morse, A. P., Cisse, M., Sy, I., Dia, I., Ermert, V., Ndione, J.-A., et al., 2017. Comparison of malaria simulations driven by meteorological observations and 
reanalysis products in senegal. International journal of environmental research and public health 14 (10), 1119.

Ebisuzaki, W., Sep. 1997. A Method to Estimate the Statistical Significance of a Correlation When the Data Are Serially Correlated. Journal of Climate $10,2147-2153$.

Enfield, D. B., Mayer, D. A., Jan. 1997. Tropical Atlantic sea surface temperature variability and its relation to El Niño-Southern Oscillation. 102, 929-945.

Failler, P., 2014. Climate variability and food security in africa: the case of small pelagic fish in west africa. Journal of Fisheries \& Livestock Production $2(2), 1-11$.

Frauen, C., Dommenget, D., Tyrrell, N., Rezny, M., Wales, S., 2014. Analysis of the Nonlinearity of El Niño-Southern Oscillation Teleconnection. 27, 6225 .

Fréon, P., Barange, M., Arístegui, J., Dec. 2009. Eastern Boundary Upwelling Ecosystems: Integrative and comparative approaches. Progress in Oceanography $83,1-14$.

García-Serrano, J., Cassou, C., Douville, H., Giannini, A., Doblas-Reyes, F. J., 2017. Revisiting the enso teleconnection to the tropical north atlantic. Journal of Climate 30 (17), 6945-6957.

Giannini, A., Chiang, J. C., Cane, M. A., Kushnir, Y., Seager, R., 2001. The enso teleconnection to the tropical atlantic ocean: Contributions of the remote and local ssts to rainfall variability in the tropical americas. Journal of Climate 14 (24), 4530-4544.

Gómez-Letona, M., Ramos, A. G., Coca, J., Arístegui, J., 2017. Trends in primary production in the canary current upwelling systema regional perspective comparing remote sensing models. Frontiers in Marine Science 4, 370 .

Ham, Y.-G., Sung, M.-K., An, S.-I., Schubert, S. D., Kug, J.-S., May 2014. Role of tropical atlantic SST variability as a modulator of El Niño teleconnections. 50, 247-261. 
King, M. P., Herceg-Bulić, I., Bladé, I., García-Serrano, J., Keenlyside, N., Kucharski, F., Li, C., Sobolowski, S., 2018. Importance of late fall enso teleconnection in the euro-atlantic sector. Bulletin of the American Meteorological Society (2018).

Lee, S.-K., Enfield, D. B., Wang, C., Aug. 2008. Why do some El Niños have no impact on tropical North Atlantic SST? Geophys. Res. Lett. 35, 16705.

Lorenz, E. N., 1956. Empirical orthogonal functions and statistical weather prediction.

Madec, G., 2008. the nemo team (2008) nemo ocean engine. Note du Pôle de modélisation. Institut Pierre-Simon Laplace (IPSL), France.

Marchal, E., 1991. Un essai de caractérisation des populations de poissons pélagiques côtiers: cas de sardinella aurita des côtes ouest-africaines.

Meiners, C., Fernández, L., Salmerón, F., Ramos, A., 2010. Climate variability and fisheries of black hakes (merluccius polli and merluccius senegalensis) in nw africa: A first approach. Journal of Marine Systems 80 (3-4), 243-247.

Messié, M., Chavez, F. P., 2015. Seasonal regulation of primary production in eastern boundary upwelling systems. Progress in Oceanography 134, 1-18.

Narayan, N., Paul, A., Mulitza, S., Schulz, M., 2010. Trends in coastal upwelling intensity during the late 20th century. Ocean Science 6 (3), 815.

Oettli, P., Morioka, Y., Yamagata, T., Jan. 2016. A Regional Climate Mode Discovered in the North Atlantic: Dakar Niño/Niña. Scientific Reports 6, 18782.

Overland, J. E., Alheit, J., Bakun, A., Hurrell, J. W., Mackas, D. L., Miller, A. J., 2010. Climate controls on marine ecosystems and fish populations. Journal of Marine Systems 79 (3-4), 305-315.

Pauly, D., Christensen, V., Mar. 1995. Primary production required to sustain global fisheries. 374, 255-257.

Polo, I., De Fonseca, B. R., Sheinbaum, J., 2005. Northwest africa upwelling and the atlantic climate variability. Geophysical research letters 32 (23). 
Rayner, N. A., Parker, D. E., Horton, E. B., Folland, C. K., Alexander, L. V., Rowell, D. P., Kent, E. C., Kaplan, A., Jul. 2003. [DATASET] Global analyses of sea surface temperature, sea ice, and night marine air temperature since the late nineteenth century. 108, 4407.

Roy, C., Reason, C., 2001. ENSO related modulation of coastal upwelling in the eastern Atlantic. Progress in Oceanography 49, 245-255.

Saha, S., Moorthi, S., Pan, H.-L., Wu, X., Wang, J., Nadiga, S., Tripp, P., Kistler, R., Woollen, J., Behringer, D., Liu, H., Stokes, D., Grumbine, R., Gayno, G., Wang, J., Hou, Y.-T., Chuang, H.-Y., Juang, H.-M. H., Sela, J., Iredell, M., Treadon, R., Kleist, D., van Delst, P., Keyser, D., Derber, J., Ek, M., Meng, J., Wei, H., Yang, R., Lord, S., van den Dool, H., Kumar, A., Wang, W., Long, C., Chelliah, M., Xue, Y., Huang, B., Schemm, J.-K., Ebisuzaki, W., Lin, R., Xie, P., Chen, M., Zhou, S., Higgins, W., Zou, C.Z., Liu, Q., Chen, Y., Han, Y., Cucurull, L., Reynolds, R. W., Rutledge, G., Goldberg, M., Aug. 2010. [DATASET] The NCEP Climate Forecast System Reanalysis. Bulletin of the American Meteorological Society 91, 1015-1057.

Sánchez-Garrido, J., Werner, F., Fiechter, J., Rose, K., Curchitser, E., Ramos, A., Lafuente, J. G., Arístegui, J., Hernández-León, S., Santana, A. R., 2019. Decadal-scale variability of sardine and anchovy simulated with an end-to-end coupled model of the canary current ecosystem. Progress in Oceanography 171, 212-230.

Shchepetkin, A. F., McWilliams, J. C., 2005. The regional oceanic modeling system (ROMS): a split-explicit, free-surface, topography-followingcoordinate oceanic model. Ocean Modelling 9, 347-404.

Taschetto, A., Rodrigues, R., Meehl, G., McGregor, S., England, M., 2016. How sensitive are the pacific-tropical north atlantic teleconnections to the position and intensity of el niño-related warming? Climate dynamics 46 (56), 1841-1860.

Tsikliras, A. C., Antonopoulou, E., 2006. Reproductive biology of round sardinella (sardinella aurita) in north-eastern mediterranean. Scientia Marina 70 (2), 281-290. 
Visbeck, M., Chassignet, E. P., Curry, R. G., Delworth, T. L., Dickson, R. R., Krahmann, G., 2003. The ocean's response to North Atlantic Oscillation variability. AGU Geophysical Monograph Series 134, 113-145.

Wang, C., Feb. 2002. Atmospheric Circulation Cells Associated with the El Niño-Southern Oscillation. 15, 399-419.

Wang, C., 2004. ENSO, Atlantic climate variability, and the Walker and Hadley circulations. In: The Hadley circulation: Present, past and future. Springer, pp. 173-202.

Wilks, D. S., 2011. Statistical methods in the atmospheric sciences. Vol. 100. Academic press.

Wooster, W. S., Bakun, A., McLain, D. R., 1976. Seasonal upwelling cycle along the eastern boundary of the north atlantic. Journal of Marine Research 34 (2), 131-141.

Zeeberg, J., Corten, A., Tjoe-Awie, P., Coca, J., Hamady, B., 2008. Climate modulates the effects of sardinella aurita fisheries off northwest africa. Fisheries Research 89 (1), 65-75. 
Supplementary material of the manuscript entitled "El Niño as a predictor of round sardinella distribution along the northwest African coast"

April 1, 2020 

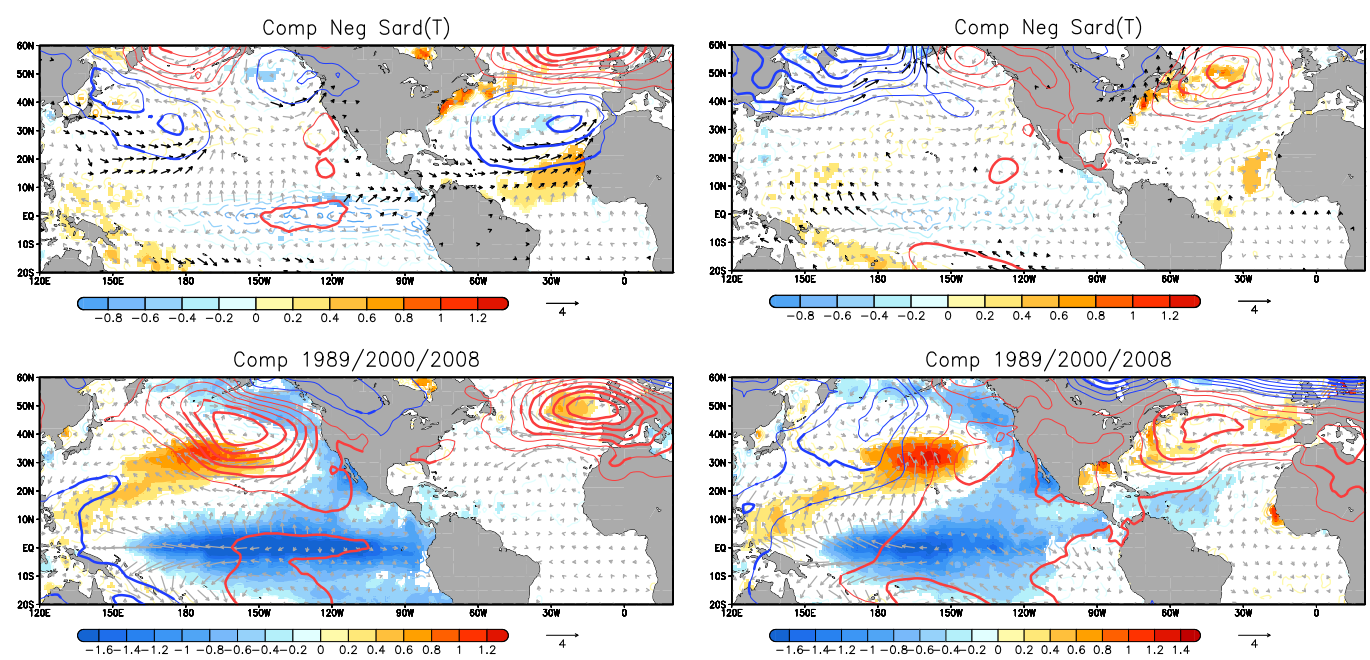

Figure S1: Upper panels: Negative composite maps based on the standardized PC1 (years below -1 standard deviation) of the anomalous round sardinella leading mode. The fields plotted are anomalous SST (shaded the $95 \%$ significant response; units in degrees), anomalous SLP (contoured; thick contoured the $95 \%$ significant response), and anomalous surface winds (gray vectors; in black the $95 \%$ significant response; units in $\mathrm{m} / \mathrm{s}$ ). Bottom panels: the same fields are plotted for La Niña years (years with the Niño 3.4 index below -1 standard deviation). Left panels refer to early winter (Nov-Jan) and right panels to late winter (Feb-Mar). 

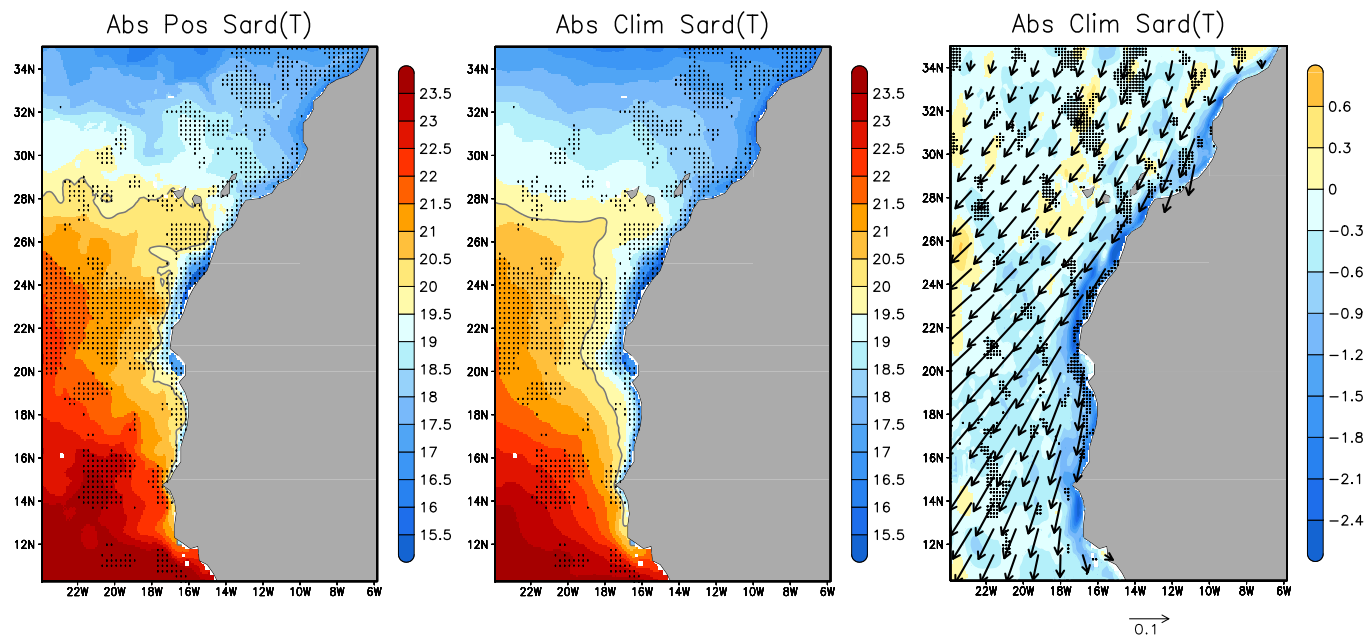

Figure S2: Absolute fields in late winter (Feb-Mar). Temperature of the water column's upper 50 meters under El Niño (left panel) and normal (center panel) conditions. Units in ${ }^{\circ} \mathrm{C}$. Black dots represent areas with significant anomalies in Figure $8 \mathrm{c}$ ). The $20^{\circ} \mathrm{C}$ isotherm is contoured for a better interpretation. Right panel represents, under normal conditions, the meridional current averaged in the water column's upper 50 meters (shaded; units in $10 \mathrm{x} \mathrm{m} / \mathrm{s}$ ) and the wind stress (vector; units in $\mathrm{N} / \mathrm{m} 2$ ). Black dots highlight areas with positive significant anomalies in Figure 8d. 


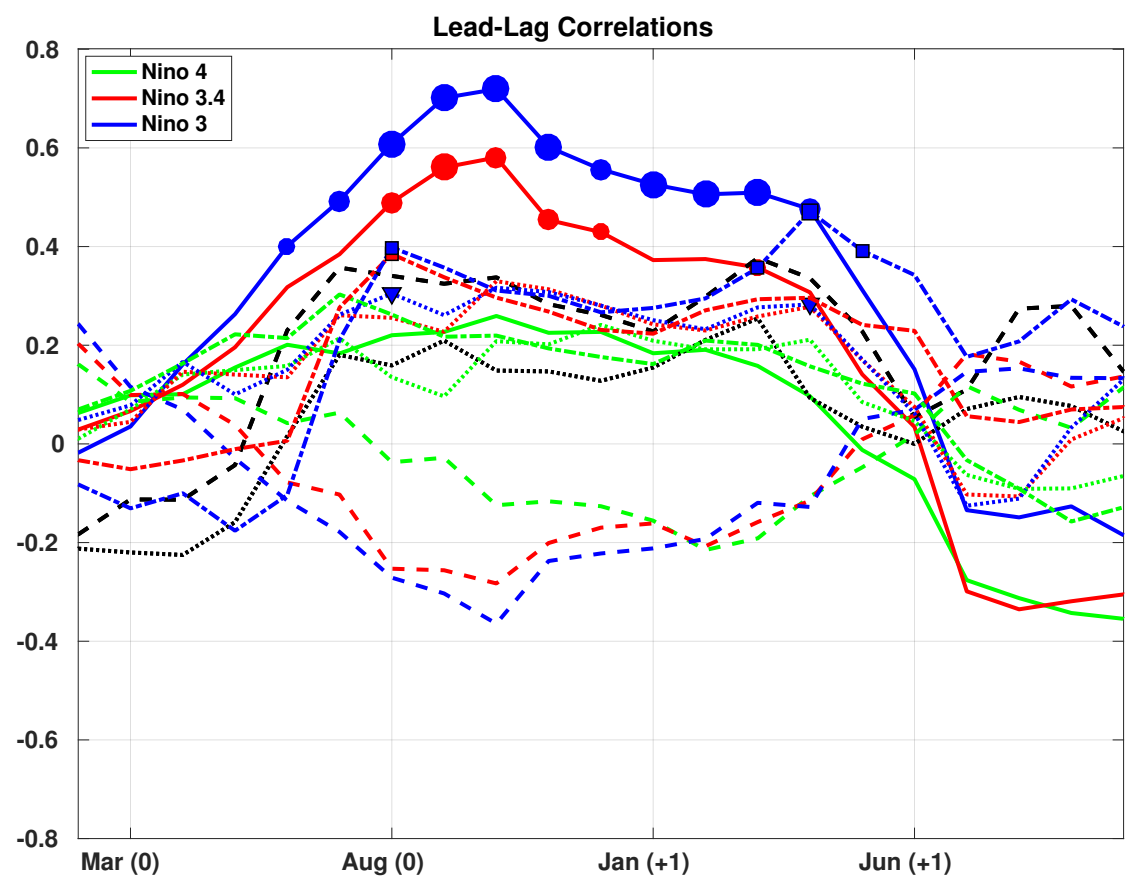

Figure S3: In solid lines the linear correlation coefficients between the leading sardinella mode (i.e., the corresponding PC) in JFM (year +1 ; see Figure 6a) and the Niño 3 (blue), Niño 4 (green), and Niño 3.4 (red) indices at different time lags. The same is shown for: 1) the meridional current of the water column's upper 50 meters off Cape Blanc in early (dashed lines) and late (dotted lines) winter, and 2) the temperature of the water column's upper 50 meters off Cape Blanc in late winter (dashed-pointed lines). The region off Cape Blanc is defined as the area within the red square indicated in Figure 8. Small, medium and large size of symbols (dots, squares and triangles) represent correlations at the 99\%, 95\% and 90\% confidence level respectively according to the non-parametric test described by Ebisuzaki et al., 2017. Finally, black dashed (dotted) line shows the correlation between the leading sardinella mode and the zonal (meridional) wind stress averaged within the green boxes indicated in Figure 8. 

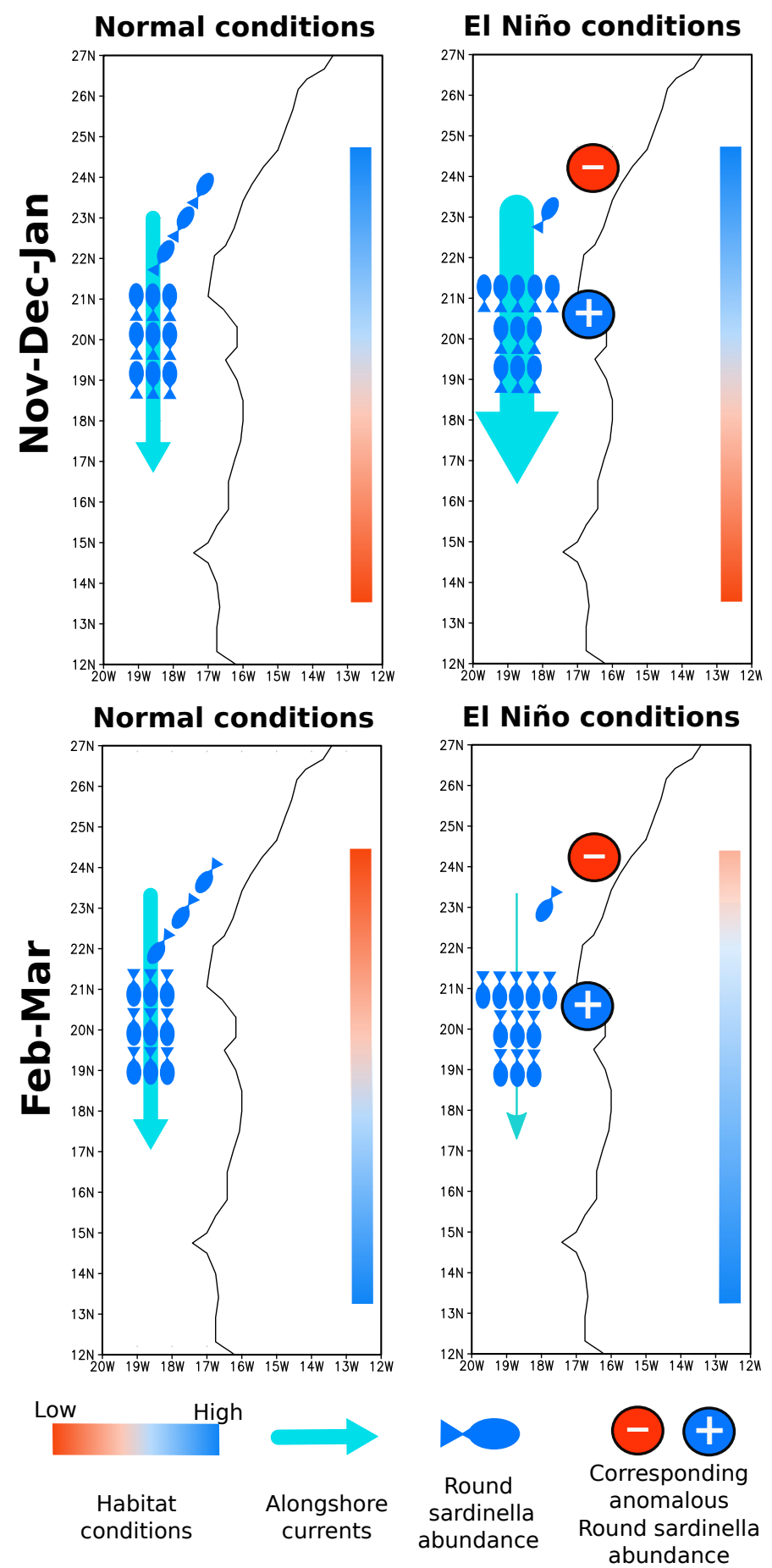

Figure S4: Simplified representation of the round sardinella response to El Niño. Upper panels corresponds to early winter and bottom panels to late winter. Left panels correspond to normal conditions and right panels to El Niño influenced conditions. Illustrated the absolute round sardinella biomass, the anomalous biomass response to El Niño, the alongshore currents, and the meridional evolution of the habitat quality of round sardinella (depending on water temperature and food abundance in the water column's upper 50 meters) along the African coast. 


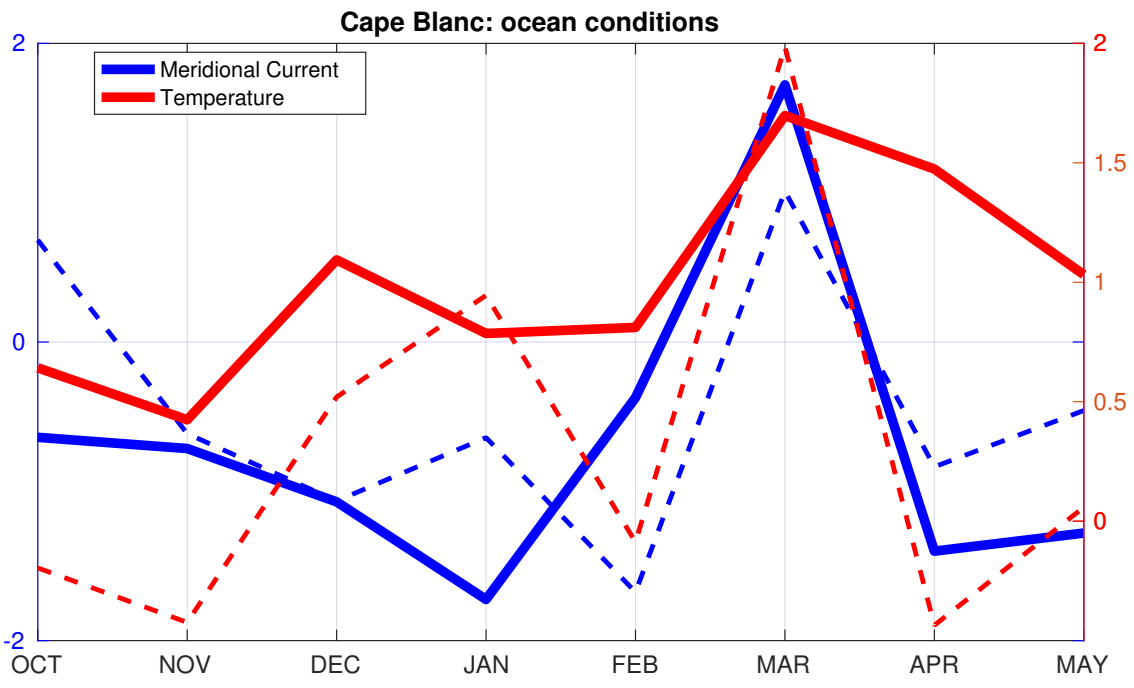

Figure S5: In solid line the averaged evolution, during El Niño years and off Cape Blanc, of the observed sea surface temperature (from the NOAA GHRSST V.2; https://podaac.jpl.nasa.gov/dataset/AVHRR_ OI-NCEI-L4-GLOB-v2.0) and the observed surface meridional current (from OSCAR third degree resolution ocean surface currents; https://podaac. jpl.nasa.gov/dataset/OSCAR_L4_OC_third-deg). In dashed line the same evolution is shown for the modeled (ROMS-PISCES) water temperature and meridional current averaged in the water column's upper 50 meters off Cape Blanc. In all cases the standardized monthly means are calculated in the area within the red square indicated in Figure 8. 